\title{
CARTA DE NICOLAU DE CUSA A RODRIGO SANCHEZ DE ARÉVALO, ORADOR RÉGIO DE CASTELLA, NA DIETA DE FRANKFURT, 1442, 20 DE MAIO
}

\author{
Nicolaus de Cusa ad Rodericum archidiaconum de Trevino, oratorem regis Castellae, \\ in dieta Francofordiensi. 1442, 20 Maii
}

Tradução de:

William Davidans Sversutti ${ }^{1}$

Pedro Calixto Ferreira Filho ${ }^{2}$

1 - Muito erudito, muito venerado por mim, Senhor Rodrigo de Arévalo, arquidiocesano de Trevino! Escrevo-te para que, nestas perturbações da Igreja, em que observas a opinião de muitos doutores flutuarem de um lado a outro influenciada pela opinião popular, sejas capaz de caçar uma última e mais verdadeira conjectura de acordo com as regras da douta ignorância, notado que - desde que o assunto da investigação seja sobre o Papa e um Concílio que representa a Igreja - e que - uma vez que todas as coisas são no Verbo de Deus, por meio do qual todas as coisas procederam ao ser -, assim, esse mesmo Verbo complica todas as coisas e todas as coisas explicadas por ele participam na variedade da alteridade. Portanto, participam de uma forma explicativa e variada na unidade do Verbo eterno que complica todas as coisas (1), de modo que o próprio Verbo, embora não possa ser participado, é participado na variedade da multitude dos participantes do melhor modo que possam participar. Portanto, todas as coisas tanto mais são quanto mais participam da entidade do próprio Verbo. Logo, o ser de cada criatura flui dessa entidade absoluta de modo imediatíssimo, uma vez que está igualmente

\footnotetext{
1 Doutorando em filosofia pela Universidade Federal do Paraná (UFPR). E-mail: williamsversutti@gmail.com

${ }^{2}$ Doutor em filosofia pela Universidade da Sorbonne e pela Universidade de São Paulo (USP), professor de filosofia na Universidade Federal de Juiz de Fora (UFJF).). E-mail: pedro.calixto@ufjf.br
} 
presente em todas as coisas; mas a alteridade das criaturas surge na alteridade dos participantes.

2 - Prosseguindo, passo a passo, afirmando a graça que é acrescentada par além da natureza, eles estão assim relacionados a Cristo. Pois, na natureza humana racional, toda criatura racional hipostaticamente unida à divindade pela graça em Cristo Jesus pode alcançar a graça da elevação à união com Deus, que é a felicidade última. Consequentemente, Jesus bendito complica todos esses tais abençoados. Portanto, todas as criaturas racionais não podem alcançar a felicidade final senão através da participação da graça de Jesus. Logo, em todos os participantes daquela graça, a graça de Jesus é explicada na variedade dos participantes. E, desse modo, a graça de Jesus é tudo o que é em todos aqueles que agradam a Deus; e todos aqueles que agradam a Deus são, em Jesus, tudo aquilo que agrada a Deus. Portanto, Una é a graça de Jesus na qual todos os redimidos participam variamente. Assim, Pedro, sumidade de todos os teólogos, desejando nos ensinar, como Lucas diz em Atos XV (2), referindo-se aos antigos padres, disse: "acreditamos que ele foi salvo de alguma maneira pela graça de nosso Senhor Jesus Cristo". E esse é o manifesto claro do Evangelho e da divina doutrina de São Paulo, uma vez que Cristo é aquele que "detém o principado" sobre "todas as coisas" e a cabeça de toda a Igreja. Há homens racionais, entretanto, peregrinos na esperança de salvação, aos quais a verdade dessa graça foi revelada por meio da encarnação de Cristo. E alguns, reconhecendo a verdade pela fé e confiantes na esperança da felicidade que advém por meio da caridade; que constituem a Igreja Militante, que possui pela graça de Jesus Cristo todas as coisas que são necessárias para isso, de modo que, depois da militância, transcenda à Igreja Triunfante e alcance a bem-aventurança em Jesus Cristo.

3 - Essa é a Igreja na qual a graça de Jesus é explicada segundo a natureza participativa deste mundo, porque, embora o homem corruptível, pela condição de sua natureza, não possa intuir a verdade sem enigma e espelho, ao menos ele a atinge mediante o enigma ou espelho ou mediante a fé. Isso requer a graça única de Jesus Cristo, em vista da qual os fiéis ou apreendedores pela fé são peregrinantes na esperança de participar do amor unificador a seu próprio modo na variada alteridade. Apropriadamente, denominamos misticamente esta Igreja de "o corpo de Cristo", porque em nenhuma outra a graça de Jesus Cristo é explicada, a não ser nela.

4 - Visto, porém, que ela é aquela pomba única, noiva imaculada (3), que tem como pontífice máximo Jesus, que entrou nos céus (4), a quem ela confessa, aderindo a Cristo no Espírito, que permanece oculto neste mundo sensível, então esta Igreja ocultada da 
Cristandade não pode ser conhecida em sua particularidade sensível de membros - que mantêm essa confissão e permanecem dignos de amor -, mas somente é atingida na força da razão por uma universalidade da razão. De fato, assim como a Igreja Triunfante superior à razão é acessível apenas na simplicidade da inteligência, da mesma forma a Igreja Militante é acessível apenas na universalidade da razão. Portanto, convém assumir no mundo sensível uma conjectura sobre esta Igreja de Cristo por meio de signos sensíveis, pois, de outra forma, a verdade da razão não seria atingida. De fato, esta Igreja conjectural neste mundo sensível, de acordo com a sua contraída compreensão, é a Igreja Verdadeira, embora, dentro de sua conjectura a partir de signos, admita tanto aqueles que recebem a Cristo em Espírito como aqueles que não recebem.

5 - Portanto, essa Igreja deste mundo sensível é constituída por aqueles que demonstram através de signos sensíveis participarem de Cristo, visto que são confidentes a Cristo, o filho de Deus. Por isso, esta mesma Igreja tem signos sagrados constituídos de modo que possamos conhecer por meio deles aqueles que são de Cristo, assim como os conhecimentos conjecturais podem ser obtidos a partir de signos. Portanto, digo que esta Igreja de Cristo, julgada desse modo conjectural, é considerada santa, mesmo que maus e hipócritas se misturem sob os signos sagrados, signos esses que são sagrados até onde as conjecturas atingem. Portanto, essa Igreja não contém todos os que aderem a Cristo. Aqueles que não manifestaram nenhum signo sensível, permanecem excluídos deste juízo. Do mesmo modo, nem todos os desta Igreja aderem a Cristo, que admite apenas o bem da união. Porém, como a condição desta vida é tal que a Igreja deva ser assim, não hesitamos em afirmar que foi ordenada por Cristo do melhor modo possível.

6 - A partir desse entendimento, segue-se que, uma vez que a própria Igreja é perfeita no seu modo, ela assim o é na medida em que tem uma cabeça. Convém que a Igreja sensível tenha uma cabeça sensível. E, por isso, a cabeça sensível desta Igreja é o pontífice, eleito dentre os homens. Nele, esta mesma Igreja existe de modo complicado, assim como no primeiro e único confessor de Cristo. Sabemos que Pedro foi o primeiro confessor de Cristo dentre os homens. E, por isso, através da confissão da "Pedra" que é Cristo, da qual Pedro recebe seu nome, o Cristo explicou a Igreja complicada em si mesmo pelo Verbo da doutrina primeiramente a Pedro (5). Portanto, não há outra Igreja senão a que teve seu início a partir de Pedro através da revelação celestial, que é a união dos fiéis em torno da confissão de Pedro. Segue-se que a explicação de Pedro, que leva o nome da Pedra complicante da Igreja, é uma Igreja Una participante da mesma confissão na alteridade da multidão de crentes. 
7 - Entretanto, como a multidão não pode participar da unidade a não ser em uma diversidade variada, consequentemente, a Igreja não pode subsistir a não ser em uma variedade da participação na unidade. Por isso, é necessária a existência de vários membros de um único corpo da Igreja, nos quais exista aquela confissão toda no todo e em cada parte dela. Segue-se que a unidade da Igreja existe na diversidade variada. E, assim como a força da unidade não pode ser participada a não ser na alteridade, a força do princípio complicante não pode ser apreendida a não ser nos principiados explicados. Não se atinge a força da natureza do pai complicante Adão de outro modo, a não ser nos homens explicados a partir dele; do mesmo modo, tampouco a força do Criador é atingida, a não ser nas suas criaturas. Portanto, segundo o modo mencionado acima, a força complicativa de Pedro, cabeça da Igreja, não pode ser apreendida exceto na Igreja explicada a partir dele.

8 - De fato, quando observamos a variedade de poderes, ordens e prelados na unidade da fé na Igreja, notando nela toda a variedade ordenadíssima e decorosa originalmente complicada em Pedro, erigimos conjecturas sobre a admirável potência e força de Pedro e apreendemos a plenitude de todas as coisas possíveis na Igreja em prol de sua preservação e o poder único de Pedro para sua direção. Não há unidade explicável na multiplicidade, a não ser que a força da unidade exista de modo maior, complicado. Sabemos deste principado universal, originalmente complicante de cada principado particular, que o mesmo é inexaurível multiplicação de principados particulares. Portanto, se os poderes dos patriarcas, arcebispos, metropolitanos, bispos e presbíteros está na Igreja, seus poderes devem ser contraídos. Entretanto, o contraído não se origina a partir de si mesmo, mas depende do absoluto. Segue-se que o poder do primeiro e supremo contém em sua plenitude todos os poderes de todos os outros; assim, não há poder exceto um, o do primeiro, que é participado de vários modos na alteridade dos prelados, porém, ao máximo, por nenhum; Aquele que é é imparticipável.

9 - Vês agora, pai, quão incorreto é dizer que o poder dos prelados particulares pode igualar ou superar o do príncipe universal. Vês o divino ditado do Papa Leão (6) com relação ao qual o poder primeiro recebe seu ser daquele poder divino mais absoluto, mas, na Igreja, ele é recebido por Pedro, o cabeça e príncipe da Igreja. Portanto, observe como o poder absoluto não existe no príncipe, a não ser no Deus Altíssimo, mas os principados todos participam diferentemente na alteridade da contração! De fato, o principado na Igreja é absoluto a seu modo, pois nele a Igreja está complicada. Do mesmo modo, qualquer principado participa a seu modo desse absoluto, quando é colocado acima dos 
populares aos quais governa. A partir disso, irracionalmente é dito que um príncipe em seu reino, onde é príncipe, preside e é igualmente subordinado. De fato, a razão não admite a coincidência dos contraditórios. Que o príncipe é das leis soluto e não pode ser condenado por seus súditos, alguns sapientíssimos intuíram e o disseram.

10 - Por tal motivo, que possa ser suficientemente claro para ti o crime execrável que é romper com a obediência e a unidade e quão presunçoso é o julgamento dos súditos contra o príncipe sagrado, sob qualquer coloração que isso adquira. Além disso, vês cada principado na Igreja colocado abaixo do primeiro, na medida em que nele está complicado e não em outro. Pois o sagrado príncipe universal existe para edificar a Igreja. Por essa razão, todo principado seja espiritual ou temporal, desde que se submeta a esse fim, é possível na Igreja. E, na medida em que resiste a esse fim, não é principado na Igreja, pois não participa da única potestade eclesiástica universal que, em todo poder que está na Igreja, é tudo aquilo que este é, de modo contraído. Vês a coincidência na unidade da potestade universal de diferentes potestades espirituais e temporais distintamente explicadas na Igreja.

11 - Não é difícil agora entenderes de que modo todo fiel, seja rei, governante ou qualquer outro, na medida em que deseja fazer parte da Igreja que essa potestade universal abrange, deve estar sujeito ao sagrado príncipe da Igreja. E isso quando o príncipe da Igreja, de acordo com a força deste próprio principiado, decide sobre as ordens. Onde, entretanto, o príncipe ordena que sejam feitas coisas que eles não acreditam pertencerem ao fim da edificação da Igreja que lhe foi confiada, a ordem não procede do principado; por esse motivo, não é necessário obedecê-lo. Se, no entanto, houver dúvida e a intenção do príncipe não for clara, deve-se presumir do príncipe sagrado que ele usou corretamente o poder a ele confiado; e ele deve ser obedecido. Logo, com isso, entendemos que na Igreja, onde existem pessoas boas e más, o príncipe sagrado pode ser bom ou mau e vemos que seu poder não pode se opor à Igreja, pois, nas coisas que não estão complicadas nessa sua potestade, ninguém está sujeito a ele, e que não há perigo em obedecer em questões duvidosas, mas grande perigo em não obedecer: sobre tudo isso, Agostinho (8) diz que não pode ser nenhuma causa pela qual é necessário iniciar um cisma. Por esse motivo, haver um cisma é um crime diabólico e imperdoável.

12 - Observe, padre, de que modo - a Igreja primitiva explicada e contraída a partir do poder universal de Pedro de modo múltiplo, segundo as múltiplas superintendências particulares - qualquer prelado em sua particularidade participando no poder contraído de Pedro, tem sim o mesmo poder que Pedro - exceto a contração. Portanto, porque nisso 
todos os que cuidam do rebanho do Senhor são os sucessores de Pedro, é evidente para os sábios que o poder universal do sagrado príncipe da Igreja não pode estar acima de qualquer principado particular, senão segundo a condição de principado, isto é, para a edificação da Igreja. Assim, na medida em que ele é o sucessor universal de Pedro, ele não poderia ter potestade sobre qualquer sucessor particular de Pedro, por meio do qual o poder particular de edificar seus subordinados sofresse qualquer mudança ou fosse impedido. Todavia, ao contrário, quando o príncipe universal supervisiona, um prelado não pode abusar do poder a ele creditado para a edificação da Igreja para a destruição de uma igreja a ele sujeita. Nisso, eu vejo reclamações de que facilmente poderiam remover o príncipe sagrado universal, alegando que o sucessor de Pedro foi originado depois da Igreja explicada por Pedro, como se ele não fosse outro Pedro, nomeado a partir da Pedra, sobre a qual a Igreja fora edificada por ordem sua. Mas, na verdade, abolir a ordem e o status ecclesia universal não é seguir Pedro.

13 - Verdadeiramente, todo primeiro pontífice romano, no ordenamento e status explicado na Igreja, não tem poder a não ser aquele de Pedro, uma vez que tal explicação foi fundada pela potestade de Pedro na edificação da Igreja, que já foi formada por ele, quando um filho nascido na Igreja é elevado ao principado de Pedro. Porque aquelas coisas que se encontram agora explicadas na Igreja pelos sucessores de Pedro da forma acima mencionada são as mesmas que procederam da potestade do príncipe universal, não é conveniente que essa mesma potestade, agora existente complicadamente no pontífice eleito, seja infringida de alguma maneira, ou seja, existem regras, um ordenamento de estatutos e outras regras universais como essas, a não ser no caso em que o próprio pontífice discernir uma razoabilidade (epikeia) ou mudança útil em prol da edificação da Igreja; neste caso, há que se notar que, quando ele não procura promover o bem comum, ofende e escandaliza os irmãos. Da mesma forma, os mais sábios sempre entenderam que - embora a mão do sagrado príncipe estendida para edificar a Igreja não possa ser inibida ou impedida por nenhuma observância ou regra dos padres, mesmo nos concílios -, no entanto, não há nele um livre poder de rejeitar, ainda que uma só vez, o poder explicado por Pedro e saudavelmente ordenado em prol do regimento da Igreja, desde que essa requeira a sua ajuda na edificação. Mas nada é mais oportuno do que executar apropriadamente o que foi testamentado inviolavelmente pelos santos padres daquilo que convém ao verdadeiro sucessor de Pedro nas coisas que procedem da potestade explicadora de Pedro, do mesmo modo. 
14 - Vês agora que, quando o príncipe da Igreja presume qualquer coisa contra os estatutos dos santos padres, onde ele não parece ser movido por razão de utilidade ou necessidade, mas sim por alguma causa particular indigna, de modo que, então, ofenda ao mandato anterior do próprio Pedro, ele excede a força de seu poder. Por essa razão não seria inconveniente, se ele persistisse obstinadamente, que a Igreja pudesse dele se afastar, quando o mesmo se afastou daquela unidade da Igreja, sem a qual a Igreja nada é e, disso, não se infere um cisma. Desse modo, aquele pontífice é entendido como sujeito aos cânones dos santos padres, como se nele não houvesse poder de abusar de acordo com seu desejo das coisas bem ordenadas e, se nisso ele persistisse obstinadamente, confirmarse-ia indigno do principado que menoscaba com esse seu abuso. De algum modo, Pedro vive no seu sucessor universal e, nos cânones patrísticos, vivem os próprios padres, e a Igreja universal, nos padres; assim, diz-se que Pedro vive na Igreja nas regras dos santos padres, desde que elas prestem auxílio no propósito de edificação da Igreja.

15 - E isso é muito próximo à regra intelectual da douta ignorância: que a Igreja está no pontífice de modo complicante, e o pontífice é igualmente explicado na Igreja, isto é, quando guarda suas sacras ordenações de modo adequado. Esse entendimento, se aplicado de modo límpido, abre o intelecto, de modo que os escritos mais ineptos de alguns são facilmente rejeitados. Deve-se reconhecer amplamente que nosso santíssimo senhor não pode ser proibido por qualquer ordenança de qualquer sínodo, quando o Concílio em prol da reunião com a Igreja Oriental está em pauta, naquela agenda em que tal assunto era o mais congruente; e ele ordenou que dissolveria todas as outras congregações nesse propósito; e dispensou os padres da Basileia, para que pudessem concordar livremente com tão santa união. Pois, assim como não há potestade pontifícia para a destruição dos atos convenientes dos padres, assim também não há poder sob o céu que possa diminuir sua autoridade, quanto menos para resgatar os dissidentes do covil. Esses homens obcecadíssimos de espírito furioso são tidos como insensatos - e néscios , quando reivindicaram para si algum tipo de poder judicial sobre o príncipe da Igreja e lhe dirigiram uma hórrida ofensa, separando-se perniciosissimamente dele e da Igreja Católica universal por todo o mundo.

16 - Isso é o suficiente no momento, já que sabes o que eles fizeram. É claro que tens o olho iluminado da inteligência, de modo que podes ver claramente que suas desculpas sofísticas não são sustentadas por nenhuma autoridade ou razão. Suas vã ambição e rebelião apóstata são evidentes para o mundo inteiro, na qual aqueles homens desesperados se esforçam com tamanha diligência e cuidado para infundir um veneno 
pior; e, em particular, ao digníssimo rei de Castella e Legiões (9) maximamente sereníssimo e digno de máximos elogios, que manifesta através de ti a solicitude, tão cara a Deus, em conservar a unidade nestas longínquas regiões da Germânia com tanto zelo, para que nada na Dieta de Frankfurt possa acontecer, infelizmente, ao rei, preocupadíssimo com as pressões diárias dos sarracenos, (10) para que tais inimigos amargos da cristandade não sejam tolerados sob algum perigosa conveniência por aqueles que procuram, por um ato temerário, abater com anátema o vigário de Cristo (11).

17 - O clementíssimo príncipe reporta a "glória imperecível de sua coroa" em prol de sua devoção interior. Esse homem de santíssimos desejos não pode ser deixado sem consolação por Deus e pela Igreja. Por estes seus santos votos não podem ser rejeitados do céu sem serem aceitos por causa de suas ações mais circunspectas nesta ilustre Dieta do Rei invicto dos Romanos (12) e dos mais gloriosos eleitores do sagrado Império Romano, de modo que, "regozijando-se no Senhor", exultante sobre todas as coisas, tu irás retornar a narrá-los. Desejo cordialmente que o faças, tanto mais uma vez que sabes que tenho trabalhado pela mesma coisa com fervor durante muitos anos.

Até breve.

\section{Texto latino:}

\section{Nicolaus de Cusa ad Rodericum archidiaconum de Trevino, oratorem regis Castellae, in dieta Francofordiensi. 1442, 20 Maii}

1 - (5) Vir doctissime mihi plurimum venerande Domine Roderice de Arevalo, archidiacone de Trevino! Ad hoc, ut in his ecclesiae perturbationibus, ubi multorum opinione vulgi doctissimorum sententias in utramque partem fluctuare conspicis, ultimam veriorem coniecturam secundum regulas doctae ignorantiae venari valeas, (10) notato quoniam de papa et concilio ecclesiam repraesentante quaestio est - quod - quoniam omnia in verbo dei sunt per quod omnia in esse prodierunt - tunc verbum ipsum est omnia complicans et ipsum verbum omnia explicata per ipsum in varietate alteritatis sunt participantia. Unitatem igitur aeterni verbi omnia (15) complicantis omnia creata explicative participant, varie quidem, ut verbum [p. 4] ipsum, quod uti est participari nequit, in varietate multitudinis participantium meliori quidem modo quo potest participetur. Omnia igitur in tantum sunt, in quantum ipsam verbi entitatem participant. 
Fluit ergo esse omnis creaturae ab illa absoluta entitate (20) immediatissime, quoniam omnibus aeque praesens est; sed in alteritate participantium exoritur alteritas creaturarum

2 - Pari passu progredere affirmando gratiam quae naturae superadditur ita se ad Christum habere. Nam omnis creatura rationalis, in natura humana rationali per gratiam in Christo Iesu divinitati hypostaticae unita, gratiam elevationis ad unionem dei, quae est (5) ultima felicitas, consequi potest. Quapropter Iesus benedictus omnes tales beatificandos est complicans. Omnes igitur rationales creaturae non aliter quam participatione gratiae Iesu felicitatem ultimam consequuntur. In omnibus ergo gratiam ipsam participantibus est gratia varietate participantium explicata. Et hoc (10) quidem modo gratia Iesu est omne id quod est in omnibus deo gratis et omnes deo grati in Iesu sunt omne id quod sunt deo grati. Una est igitur gratia Iesu ab omnibus salvatis varie participata. Hoc Petrus, omnium theologorum (summitas), nobis insinuare volens ut Lucas in Actibus refert XV capite, de veteribus patribus 15 referens aiebat: "Per gratiam domini” nostri "Iesu Christi credimus salvari, quemadmodum et illi". Et haec est sancti evangelii manifestatio et divini Pauli doctrina, quoniam Christus "in omnibus" est "principatum tenens" et caput omnis ecclesiae. Sunt autem homines rationales peregrinantes in spe salvationis, quibus revelata est (20) veritas huius gratiae per Christi incarnationem. Et hii quidem in fide sunt veritatem agnoscentes et in spe exspectantes felicitatem medio caritatis; qui militantem constituunt ecclesiam, quae omnia habet per gratiam Iesu Christi quae adhuc sunt necessaria, ut post militiam in triumphantem transcendat et beatitudinem in Iesu (25) Christo consequatur.

3 - Haec quidem ecclesia est, in qua est gratia Iesu explicata secundum istius mundi participantem naturam, quia, cum non possit corruptibilis homo veritatem intueri ob suae naturae condicionem sine aenigmate et speculo, saltem ipsam in aenigmate et speculo (5) seu fide attingat. Quapropter fideles seu in fide apprehendentes, in spe peregrinantes adhaesivo amore participare suo quidem modo in varia alteritate constat gratiam unicam Iesu Christi esse. Bene et hanc ecclesiam Christi corpus dicimus mystice quidem, quia non est nisi gratia Iesu Christi explicata.

4 - Quoniam autem haec est ipsa unica columba, sponsa sine macula, quae habet pontificem maximum Iesum qui caelum penetravit, cuius tenet confessionem Christo adhaerens in spiritu, qui occultatus remanet in hoc sensibili mundo, tunc haec ecclesia (5) occultata Christi (non) in sua sensibili particularitate membrorum - cum sciri nequeat, quis hanc teneat confessionem et amore dignus exsistat -, sed solum in vi rationis quadam universalitate rationis attingitur. Sicut enim triumphantium ecclesia supra rationem in 
simplicitate intelligentiae tantum accessibilis est, ita et haec (10) militans in rationis universalitate. Oportet autem in sensibili mundo sensibilibus signis de ipsa Christi ecclesia coniecturam sumere, cum aliter attingi nequeat rationis veritas. Quapropter coniecturalis illa ecclesia in hoc sensibili mundo secundum huius mundi contractam cognitionem vera quidem ecclesia est, licet (15) intra suam coniecturam ex signis receptam admittat tam Christo in spiritu adhaerentes quam non.

5 - Constituitur igitur haec huius sensibilis mundi ecclesia ex his, quae sensibilibus signis se Christum participare demonstrant, uti sunt Christum filium dei confitentes. Quapropter haec ipsa ecclesia sacra quaedam habet signa ad hoc instituta, ut per ea cognoscamus (5) eos qui Christi sunt eo quidem modo, quo ex signis coniecturalis trahi cognitio potest. Dico igitur quod haec ecclesia Christi huius coniecturalis modi iudicio sancta censetur, etiamsi mali et ficti sub signis sacris se intermisceant, quorum signa tantum quae sacra sunt attingit. Non igitur omnes Christo adhaerentes includit (10) haec ecclesia. Qui enim nullo sensibili signo manifesti fiunt, penitus hoc iudicio exclusi remanent. Sic nec omnes de hac ecclesia Christo adhaerent, qui bonos tantum ad unionem admittit. Quoniam autem huius vitae condicio talis est quod hanc ecclesiam ita esse oportet, ipsam a Christo meliori quidem modo, quo ipsa ut (15) sic ordinari potuit, ordinatam non haesitamus.

6 - Qua ex re sicut haec ipsa ecclesia perfecta est suo quidem modo, ita et caput habet. Sensibilem enim ecclesiam sensibile caput habere convenit. Et ob hoc caput huius ecclesiae est pontifex, qui ex hominibus assumitur. In quo est haec ipsa ecclesia (5) complicative ut in primo uno confessore Christi. Petrum autem primum Christi confessorem scimus inter homines. Et ob hoc Petrus, a confessione petrae quae Christus est nomen accipiens, complicatam in se ecclesiam explicavit verbo doctrinae primo omnium. Non est igitur aliud ecclesia, quae a Petro initium cepit (10) superna revelatione, quam unio fidelium in Petri confessione. Explicatio igitur Petri a petra dicti ecclesiam complicantis est ecclesia una eandem confessionem in alteritate multitudinis credentium participantis.

7 - Quoniam autem multitudo unitatem non nisi in varia alteritate potest participare, non potuit ecclesia nisi in varia participatione unitatis subsistere. Quapropter varia esse membra unius corporis ecclesiae necesse fuit, in quibus una illa confessio tota in toto et in (5) qualibet eius parte exsisteret. Unitas igitur in varia alteritate ecclesia exsistit. Et sicut unitatis virtus non nisi in participata alteritate attingi potest, sic nec complicantis principii virtus aliter quam in explicatis principiatis potest apprehendi. Non enim virtus 
unitatis naturae Adae complicantis patris aliter quam in explicatis a se (10) hominibus attingitur; sic nec creatoris nisi in ipsis creaturis. Hoc igitur modo Petri, capitis ecclesiae huius, complicativa virtus non nisi in explicata a se ecclesia potest apprehendi.

8 - Quando enim varietatem potestatum, ordinum et praelationum in unitate fidei in ecclesia esse conspicimus, illam omnem varietatem ordinatissimam atque decoram in Petro complicatam originaliter conspicientes, ad coniecturas de Petri admirabili potentia (5) et virtute erigimur et plenitudinem omnium possibilium in ecclesia pro eius conservatione et directione unicam Petri apprehendimus potestatem. Non enim est unitas in multitudine explicabilis, quoniam unitatis virtus complicative maior exsistat. Hinc principatum universalem, omnem particularem principatum originaliter (10) complicantem, inexhauribilem multiplicatione particularium cognoscimus. Si igitur in ecclesia est patriarcharum, archiepiscoporum, metropolitanorum, episcoporum presbyterorumque potestas, has quidem contractas esse constat. Contractum autem ex se ortum non habet, sed ex absoluto dependet. Quare potestas (15) primi et supremi in sua plenitudine ambit omnem omnium potestatem; immo non est potestas nisi una et primi, quae in alteritate rectorum varie participatur, a nullo tamen maxime; imparticipabilis enim est uti est.

9 - Vides nunc pater, quam inepte dicitur potestatem particularium rectorum aequari aut eminere posse potestati universalis principis. Vides divinum dictum Leonis Papae, quomodo omnis potestas primo quidem ab absolutissima illa divina potestate esse recipit, (5) sed in ecclesia per Petrum, caput et principem ecclesiae. Adverte igitur, quomodo non est potestas principis absoluta nisi dei summi, sed principatus omnis varie hanc in alteritate contractionis participat! Principatus enim in hac ecclesia absolutus quidem est suo modo, quoniam in ipso ecclesia complicatur. Ita quidem principatus (10) quicumque absolutionem suo modo participat, quoniam supra ipsum populum cui principatur constituitur. Unde irrationabiliter dicitur principem in eo regno, ubi princeps est, praeesse pariter et subesse. Ratio enim contradictoriorum coincidentiam non admittit. Item quidam sapientissimi intellexerunt, qui principem (15) solutum legibus et non posse a subditis iudicari dixerunt.

10 - Ideo satis tibi patere potest, quam exsecrabile delictum sit scissura oboedientiae et unitatis et praesumptuosum iudicium subiectorum contra principem, sub quocumque colore istud fiat. Vides etiam principatum omnem in ecclesia sub primo subsistere, in (5) quantum in ipso complicatur et non aliter. Nam principatus universalis ad aedificandam ecclesiam exsistit. Quare omnis principatus sive spiritualis sive temporalis, in quantum 
huic fini subservit, in ecclesia esse potest. Et in quantum huic fini resistit, non est principatus in ecclesia, cum non participet unicam ecclesiasticam (10) universalem potestatem, quae in omni potestate, quae in ecclesia est, est id quod est ipsa contracte. Vides coincidentiam in unitate universalis potestatis, differentes spirituales et temporales potestates in ecclesia distincte explicatas.

11 - Non est tibi nunc difficile intelligere, quomodo principi ecclesiae omnis fidelis subiectus esse debeat, sive rex sive praeses aut alius, in quantum ipsi de ecclesia esse velint, quam illa potestas universalis ambit. Et hoc, quando princeps ecclesiae secundum principatus (5) ipsius virtutem praecepta discernit. Ubi vero ipse princeps ea fieri mandaret, quae ad finem aedificationis ecclesiae creditae non tenderent, non procederet a principatu; quare ei oboedire tunc non foret necesse. Si vero dubium foret et de mente principis constaret, pro principe praesumendum quod recte potestate utatur, et (10) sibi oboediendum est. Cum ergo intelligamus in ecclesia, ubi sunt boni et mali, principem etiam posse et bonum et malum esse et videamus potestatem eius ecclesiae obesse non posse, cum in his, quae in ipsa potestate non complicantur, ei non subsit quisquam, et in dubiis oboediendo nihil sit periculi, sed periculum magnum (15) non oboediendo: hinc ait Augustinus nullam posse causam dari, ob quam necessarium sit ad schisma pervenire. Quare schisma diabolicum inexcusabile crimen exsistit.

12 - Adverte pater, quomodo - explicata ecclesia primitiva et contracta ipsa universali Petri potestate varie secundum varias particulares superintendentias - quilibet rector in sua particularitate Petri potestatem contracte participans eandem - salva contractione (5) quam Petrus habet potestatem. Unde, quia in hoc omnes Petri sunt successores, qui dominici gregis curam gerunt, visum est sapientibus universalem potestatem principis ecclesiae super istam cuiusque particularem non esse nisi secundum principatus condicionem, scilicet ad aedificationem. Ita scilicet quod ipse, qui est (10) universalis Petri successor, in particularem Petri successorem non habeat potestatem, per quam potestas aedificatoria particularis in sibi subiectis immutationem capiat aut impediatur. Secus autem, quando superintendit princeps universalis, ne rector credita potestate in aedificationem abutatur in destructionem subiectae (15) ecclesiae. In hoc video murmurationes exoriri, quae facile tolluntur universali principe advertente se Petri successorem, post ecclesiam explicatam a Petro, non quasi ipse sit alter Petrus a petra dictus, super quam petram ecclesia erat aedificanda cum ordine suo. Nam (20) tollere or|dinem et statum universalis ecclesiae explicare non est sequi Petrum. 
13 - Omnis enim Romanus et primus pontifex in explicatum ecclesiae ordinem et statum a Petro non habet potestatem, quoniam haec explicatio per Petri potestatem in aedificationem ecclesiae iam facta per ipsum reperitur, quando ad Petri principatum natus (5) in ecclesia filius sublimatur. Quia itaque ea, quae explicata reperiuntur in ecclesia per Petri successores modo nunc dicto, sunt ipsa, quae ex universalis principis potestate prodierunt, non est conveniens illa per eandem potestatem, nunc in electo pontifice complicatorie exsistentem, quovismodo infringi, sive illae sint (10) regulae sive ordo statuum aut alia universalia quaecumque nisi in casu, quo pontifex ipse videret aut epikeiam aut immutationem utilem pro aedificatione ecclesiae; quo casu advertere habet, ne, cum utilitatem procurare studet, fratres offendat et scandalizet. Eo quidem modo sapientiores semper intellexerunt quod - quamvis principis ecclesiae (15) manus ad aedificationem extensae nulla observantia aut regula patrum, etiam in conciliis inhiberi prohiberique possent - non est tamen apud ipsum libera potestas reiciendi semel per Petri explicatam potestatem salubriter pro regimine ecclesiae ordinata, quamdiu illa ad aedificationem praestans adiumentum. Sed nullam (20) sedem magis oportet sanctorum patrum bene statuta inviolabiliter exsequi, tamquam verum Petri successorem in his, quae ex eadem Petri potestate explicatorie prodiere.

14 - Vides nunc, quando princeps ecclesiae contra sanctorum patrum statuta aliquid praesumeret, ubi non constaret eum ex causa utilitatis aut necessitatis moveri, sed potius ex aliqua particulari non digna causa, quomodo tunc in ipsa priora eiusdem Petri (5) mandata offendit, exiens vires potentiae suae. Quapropter non esset inconveniens, si pertinaciter in hoc persisteret, ab eo recedi posse per ecclesiam, quando recessus ipse unitati ecclesiae, sine qua ecclesia esse nequit, scissuram non inferre[n]t. Eo quidem modo pontificem canonibus sanctorum patrum subesse intelligendum (10) est, quasi in eo non sit potestas bene ordinatis pro libito abutendi et, si in hoc pertinaciter persisteret, quod tunc se principatu, quem in abusu parvifaceret, indignum constitueret. Quemadmodum enim Petrus in universali successore vivit, ita et in canonibus patrum, quoniam patres ipsi et universa ecclesia in patribus; sic et (15) Petrus in ecclesia in ipsis sanctorum regulis vivere dicitur, quamdiu utilitati aedificandae ecclesiae praestant adiumentum.

15 - Et hoc est iuxta regulam intellectualem doctae ignorantiae in pontifice esse ecclesiam complicative et ipsum esse pariter in ecclesia, hoc est cum ipsa in suis sacris ordinationibus consentanee vigilare. Haec si ad liquidum extendantur, intellectum aperiunt (5), ut aliquorum ineptissimae scripturae facile spernantur. Videaturque quam 
aperte sanctissimum dominum nostrum nulla cuiuscumque synodi constitutione prohiberi potuisse quod conilium pro reductione Orientalis ecclesiae in eo loco, ubi magis rebus agendis congruebat, non constitueret atque ob hoc omnes (10) alias congregationes dissolveret et patres a Basilea absolveret, ut ad tam sanctam unionem libere concurrere possent. Nam sicut non est potestas pontificis ad destructionem bene actorum per patres, ita nec est potestas sub caelo, quae eius posset auctoritatem minuere, quo minus errantes ad ovile reducat. (15) Visi sunt illi obcaecatissimi viri in spiritu furoris fuisse extra omnem sensum, quando sibi supra principem ecclesiae - nescio qualem - iudiciariam vindicabant potestatem et horridum nefas attentaverunt in principem suum saevientes, se ipsos ab eodem et universa per orbem catholica ecclesia perniciosissime secantes.

16 - Nunc satis est, quoniam gesta tibi res notissima est. Habes etiam illuminatum clare intelligentiae oculum, ut sophisticas palliationes eorum optime conspicias nulla auctoritate aut ratione fulciri. Patet etiam universo orbi, cui viri illi desperati virus pessimum (5) inicere tanta diligentia et cura sategerunt, eorum vanissima ambitio et apostatica rebellio eorum et maxime serenissimo maximarumque laudum dignissimo regi Castellae et Legionis, qui te medio deo amabilem sollicitudinem conservandae unitati in his longe distantibus Germaniarum regionibus tanto zelo impendit, ut nihil occupatissimo (10) regi in quotidiana Agarenorum depressione infestius diatim occurrat quam tales christianae rei publicae inimicissimos sub quadam periculosa coniventia tolerari per eos, quos ipsi temerario ausu cum Christi vicario anathemate ferire conati sunt.

17 - Reportabat princeps ille clementissimus pro sua interna devotione "immarcescibilem gloriae coronam". Non enim poterat inconsolatus a deo et ecclesia relinqui vir sanctissimorum desideriorum. Nec poterunt vota sacratissima eius tua circumspectissima (5) agitatione in hac praeclara invictissimi Romanorum regis et gloriosissimorum electorum Sacri Romani Imperii constituta dieta, tamquam e caelo missa non acceptari, ut sic "in domino gaudens" omnia feliciter peracta relaturus revertatur. Quod tibi tanto cordialius advenire opto, quanto me nosti annis (10) multis pro eodem laborasse.

Etc.

Finis. 